\title{
Two-Week Prevalence of Disease Among the Rural Elderly - 6 Provinces, China, 2018-2019
}

\author{
Tong $\mathrm{Xu}^{1}$; Hui $\operatorname{Han}^{1, *}$
}

\section{Summary \\ What is already known about this topic?}

As population aging becomes serious in China, the elderly health problems stand out prominently. The 2week prevalence of the elderly is rising year by year, but it has been rarely studied for the rural seniors in the central and western China.

\section{What is added by this report?}

The 2-week prevalence rate of rural elderly in the central and western China is $28.5 \%$, and it varies among different ethnic groups. The top prevalence is chronic diseases, and the severity of diseases is higher in female and high age group (80-year-old and over) people.

What are the implications for public health practice?

Considering the health status, health awareness and ethnic differences of the elderly in the central and western China, medical and health resources should be rationally allocated to prevent and treat chronic diseases and support differentiated health services. This is of great significance for the development of health service plan.

Population aging is a sign of human social progress and an inevitable trend of world population development (1). As the elderly population increases, their health problems become larger concerns to society. The 2-week prevalence of disease is a key indicator reflecting the health status and the demand for health services of the residents surveyed. In this study, the 2-week prevalence of disease among the elderly in central and western China was analyzed to provide a basis for improving the health of the elderly and the quality of health services.

Through multistage random cluster sampling, 14,656 rural elderly people aged 60 years and over in 20 project counties were selected for the survey.

The survey results revealed that the 2-week prevalence of any disease was $28.5 \%$, and the group of disease with the highest prevalence was chronic diseases. An estimated $61.1 \%$ of the people surveyed had a chronic disease that continued during the 2-week period. The severity of disease was higher in females than males and higher in the higher age group (aged 80 years or more) than the lower age group (aged 60-79 years).

Thus, the rural elderly population's health should be protected by preventing chronic diseases and improving access to and quality of medical and health services.

This study was based upon a survey under the "Community Participation to Promote Rural Elderly Health - Phase II" project of China's National Health Commission. The survey was completed from November 2018 to January 2019 for the elderly aged 60 years and over who were capable of answering the questions on their own and with a residence history exceeding half a year. The participants were selected through multistage random cluster sampling from 130 administrative villages in 65 towns of 20 project counties. These project counties referred to poor counties with a large elderly population and a willingness to be surveyed, and 2-3 towns of each county were selected by random sampling according to the population of the county with 2 villages of each town being selected by random cluster sampling in 6 project regions [provincial-level administrative divisions (PLADs) including Yunnan Province, Xinjiang Uyghur Autonomous Region, Shanxi Province, Qinghai Province, Hubei Province, and Chongqing Municipality].

The survey consisted of face-to-face questionnaire that included two parts: general information of the respondent (e.g. demographic features, health-related conditions, etc.) and 2-week prevalence (e.g. type of 2week prevalence of disease, onset of 2-week prevalence of disease, and severity of disease). The 2-week prevalence of disease meant that the respondent, within the 14 days before the day when he/she is surveyed: 1) had a disease and visited a medical organization for treatment; 2) had a disease and began self-treatment (e.g. self-administration of drugs, or 
adjuvant therapy like hot compress) instead of visiting a medical organization; or 3) had a disease and rested at home or stayed in bed for more than 1 day instead of visiting a medical organization or taking any selftreatment (2).

The 2-week prevalence of disease was defined as the number of persons who had a disease in the past two weeks to the total number of persons surveyed or through a second definition comparing the number person-times suffering a disease in the past two weeks to the total number of persons surveyed. The numerator using the number of persons was adopted in several previous studies and this study, and the additional numerator of person times was used for comparison with the National Health Service Survey data. In this survey, the diseases and the severity were diagnosed based on ICD-10. The types of diseases investigated were subject to the reporting of the respondents.

Statistical analyses were performed using SPSS statistical software (version 22.0, SPSS Inc, Chicago, IL, USA). The significance level was set to $\alpha=0.05$. The statistical method is the chi-square test.

The effective sample size of this survey is 14,656 persons including 7,404 males $(50.5 \%)$ and 7,252 females (49.5\%;) and exhibiting an average age of $69.86 \pm 6.98$ years old (including 8,435 persons or $57.6 \%$ of the total population aged 60 to 69 years) as shown in Table 1.

Among the 14,656 persons, the number of persontimes reported to experience disease in the 2 weeks was 4,182 , so the 2 -week prevalence of disease was derived to be $28.5 \%$. The number of persons who had an illness in the 2 weeks was 2,546, so the 2-week prevalence was determined to be $17.4 \%$. Particularly, the 2 -week prevalence of disease were $14.9 \%$ for males

TABLE 1. Basic information and the illnesses over the 2-week study period of the rural elderly -6 provinces, China, 2018-2019.

\begin{tabular}{|c|c|c|c|c|c|c|}
\hline Demographic characteristics & $\begin{array}{l}\text { Number of } \\
\text { surveyed }\end{array}$ & $\begin{array}{c}\text { Composition } \\
\text { ratio (\%) }\end{array}$ & $\begin{array}{c}\text { Number of } \\
\text { respondents with } \\
\text { illnesses }\end{array}$ & $\begin{array}{c}\text { Prevalence } \\
(\%)\end{array}$ & $x^{2}$ & $p$ \\
\hline Gender & & & & & 64.522 & $<0.001$ \\
\hline Male & 7,404 & 50.5 & 1,102 & 14.9 & & \\
\hline Female & 7,252 & 49.5 & 1,444 & 19.9 & & \\
\hline Age (years old) & & & & & 14.208 & 0.001 \\
\hline $60-$ & 8,435 & 57.6 & 1,380 & 16.4 & & \\
\hline $70-$ & 4,492 & 30.6 & 839 & 18.7 & & \\
\hline $80-$ & 1,729 & 11.8 & 327 & 18.9 & & \\
\hline Ethnicity & & & & & 372.133 & $<0.001$ \\
\hline Han & 3,235 & 22.1 & 612 & 18.9 & & \\
\hline Uighur & 5,980 & 40.8 & 815 & 13.6 & & \\
\hline Tujia & 2,532 & 17.3 & 470 & 18.6 & & \\
\hline Kazakh & 838 & 5.7 & 118 & 14.1 & & \\
\hline Lahu & 701 & 4.8 & 271 & 38.7 & & \\
\hline Tibetan & 637 & 4.3 & 60 & 9.4 & & \\
\hline Other & 733 & 5.0 & 200 & 27.3 & & \\
\hline Educational level & & & & & 111.850 & $<0.001$ \\
\hline Illiterate or semiliterate & 7,516 & 51.3 & 1,542 & 20.5 & & \\
\hline Primary school & 5,394 & 36.8 & 726 & 13.5 & & \\
\hline Junior high school and above & 1,746 & 11.9 & 278 & 15.9 & & \\
\hline Marital status & & & & & 83.967 & $<0.001$ \\
\hline Unmarried/widowed/solitary & 1,758 & 12.1 & 287 & 16.2 & & \\
\hline Only husband and wife living together & 6,566 & 44.8 & 956 & 14.6 & & \\
\hline Living with children & 6,322 & 43.1 & 1,303 & 20.6 & & \\
\hline Total & 14,656 & 100.0 & 2,546 & 17.4 & & \\
\hline
\end{tabular}


and $19.9 \%$ for females, and it was the highest (18.9\%) in the age group of 80 years and over as shown in Table 1 .

The 5 disease categories with the highest 2-week prevalence were hypertension $(3.9 \%)$, common cold $(2.5 \%)$, arthritis/rheumatoid (2.3\%), gastroenteritis/ peptic ulcer (2.1\%), and asthma/bronchitis/emphysema and other lung diseases (1.6\%). Among the 2,546 persons who reported an illness in the past 2 weeks, $61.1 \%(1,557 / 2,546)$ had a chronic disease which started before the 2 weeks but continued during this period, $25.9 \%(659 / 2,546)$ had an acute disease, and $13.0 \%(330 / 2,546)$ had an acute disease that continued in the 2 -week period. See Table 2 for more details.

The severity of disease in the surveyed elderly in the 2 weeks was different between genders and between age groups. The number of sick days in the 2 weeks per 1,000 people was 1,601 days for females, which was more than the 1,176 days reported for males. The number of sick days in the 2 weeks per 1,000 people was 1,683 days for the higher age group and more than 1,253 days for the lower age group. In addition, the bedridden rate and the number of bedridden days were higher for females than for males, and higher for the higher age group than for the lower age group. See Table 3 for more details.

\section{DISCUSSION}

The 2-week prevalence was a key indicator that reflected the health status of the elderly and assessed the demand for health services. This survey revealed the 2-week prevalence of disease in elderly people aged
60 years and over in rural areas in central and western China as $28.5 \%$ (based on the number of persontimes), which is lower than the 2 -week prevalence rate of $45.8 \%$ in the Fifth National Health Service Survey (2) $(p<0.05)$. This difference was believed to be driven by seasonal factors and the lower availability/quality of health services, weaker health awareness of residents, and other factors in central and western China (3-4). In view of ethnic groups, the Lahu ethnicity was discovered to have the highest 2-week prevalence of any disease, with the top 5 disease categories being gastroenteritis/peptic ulcer (101.3\%o), arthritis/ rheumatoid (98.4\%o), common cold (74.2\%o), intervertebral disc disease $(54.2 \% 0)$, and hypertension $(22.8 \%$ o). The high prevalence of hypertension may be attributable to the dietary habits of the Lahu people, which includes a relatively high consumption of salt, such as barbecue and pickles as found in our survey. Additionally, the elderly were susceptible to colds, arthritis, and gastrointestinal diseases in the seasonal transition from autumn to winter in Yunnan Province when the survey was performed (5).

The disease category with the highest 2-week prevalence in the rural elderly was chronic diseases such as hypertension. Among the elderly who reported a disease in the surveyed 2 weeks, $61.1 \%$ had a chronic disease that continued in the 2 -week period. This was similar to the results of most studies, indicating that chronic diseases are the major contributor to the 2week prevalence of disease (6-9). However, the 2-week prevalence was low in the surveyed regions, possibly because the regions are poor rural areas in central and western China where the living standards of residents are lower and led to a lower prevalence of chronic

TABLE 2. Prevalence and composition of the survey subjects in the 2-week survey period - 6 provinces, China, 2018-2019.

\begin{tabular}{|c|c|c|c|c|c|c|}
\hline \multirow[b]{2}{*}{ Disease name } & \multicolumn{2}{|c|}{ Male } & \multicolumn{2}{|c|}{ Female } & \multicolumn{2}{|c|}{ Total } \\
\hline & $\begin{array}{c}\text { Prevalence } \\
(\%)\end{array}$ & $\begin{array}{l}\text { Composition } \\
\text { ratio (\%) }\end{array}$ & $\begin{array}{c}\text { Prevalence } \\
(\%)\end{array}$ & $\begin{array}{c}\text { Composition } \\
\text { ratio }(\%)\end{array}$ & $\begin{array}{c}\text { Prevalence } \\
(\%)\end{array}$ & $\begin{array}{l}\text { Composition } \\
\text { ratio }(\%)\end{array}$ \\
\hline Hypertension & 3.3 & 22.2 & 4.6 & 22.9 & 3.9 & 22.6 \\
\hline Cold & 2.0 & 13.5 & 3.0 & 15.0 & 2.5 & 14.4 \\
\hline Arthritis/rheumatoid & 1.8 & 12.1 & 2.8 & 14.1 & 2.3 & 13.2 \\
\hline Gastroenteritis/peptic ulcer & 1.7 & 11.3 & 2.4 & 12.1 & 2.1 & 11.8 \\
\hline $\begin{array}{l}\text { Asthma/bronchitis/emphysema and other lung } \\
\text { diseases }\end{array}$ & 1.5 & 10.0 & 1.7 & 8.7 & 1.6 & 9.3 \\
\hline Intervertebral disc disease & 1.2 & 8.0 & 1.6 & 7.9 & 1.4 & 7.9 \\
\hline Heart disease/coronary heart disease & 0.8 & 5.1 & 1.4 & 7.0 & 1.1 & 6.2 \\
\hline Cerebrovascular disease(including stroke) & 0.6 & 4.2 & 0.5 & 2.7 & 0.6 & 3.3 \\
\hline Prostatitis, nephritis, kidney stones, cystitis & 0.6 & 4.2 & 0.2 & 1.0 & 0.4 & 2.4 \\
\hline Gallstones/cholecystitis & 0.3 & 1.8 & 0.5 & 2.6 & 0.4 & 2.2 \\
\hline
\end{tabular}


TABLE 3. Indicators of the severity of illness in the elderly in the 2 -week survey period* -6 provinces, China, 2018-2019.

\begin{tabular}{lcccc}
\hline $\begin{array}{l}\text { Demographic } \\
\text { characteristics }\end{array}$ & $\begin{array}{c}\text { Age group } \\
\text { (years old) }\end{array}$ & $\begin{array}{c}\text { Days of } \\
\text { illness }\end{array}$ & $\begin{array}{c}\text { Bedridden } \\
\text { days }\end{array}$ & $\begin{array}{c}\text { Bedridden } \\
\text { rate (\%o) }\end{array}$ \\
\hline Male & & 1,176 & 183 & 30.9 \\
& $60-$ & 1,070 & 151 & 26.5 \\
& $70-$ & 1,261 & 164 & 31.4 \\
& $80-$ & 1,484 & 365 & 48.6 \\
Female & & 1,601 & 290 & 50.2 \\
& $60-$ & 1,436 & 237 & 46.3 \\
& $70-$ & 1,799 & 330 & 51.3 \\
& $80-$ & 1,881 & 445 & 64.3 \\
& & 1,387 & 236 & 40.3 \\
& $60-$ & 1,253 & 194 & 36.4 \\
& $70-$ & 1,530 & 247 & 41.6 \\
& $80-$ & 1,683 & 413 & 57.8 \\
\hline
\end{tabular}

* The indicators in the table are all due to illness within two weeks. Among them: the number of sick days and bedridden days are the number of sick days and bedridden days per thousand surveyed population within two weeks. Bedridden rate $=$ number of bedridden in 2 weeks / number of surveyed $\times 1,000 \%$.

diseases (e.g. hypertension and diabetes) than urban areas and other non-poor rural areas.

The severity of disease in the elderly in the 2-week period was different between genders and between age groups. The number of sick days, bedridden rate, and bedridden days were higher for females than males $(p<0.05)$, and higher for the higher age group than the lower group $(p<0.05)$. Elderly people that were female and in the higher age group were more susceptible to diseases, and the elderly people at high age lived longer but were not healthy, which is consistent with findings from Shi et al (10). Thus, to fully reflect the health level of the rural elderly, both the occurrence and severity of disease in the elderly should be considered.

This was the first survey conducted for the 2-week prevalence of disease in the rural elderly in central and western China using a large sample size. The 2-week prevalence of disease was lower than the average derived in the National Health Service Survey, which may be related to lower health awareness and service needs of people surveyed. The indicator varied by ethnicity, gender, etc. Medical and healthcare organizations should pay more attention to the health status of key populations among the elderly through strengthening the allocation of health resources, taking preventative and treatment measures against chronic diseases, and raising the health awareness of residents to meet the real health service needs of the rural elderly in central and western China.
This study was subject to some limitations. The 2week prevalence obtained in this survey was subject to limitations in the survey method that was timeconsuming and covered a large geographical area, which may cause the results to have wide variability. In addition, because this study only covered a period of two weeks, the results may be affected by when the participants were surveyed as they could not all be recorded at the same time.

Funding: This study was funded by Kadoorie Charitable Foundation.

doi: $10.46234 / \mathrm{ccdcw} 2020.184$

\# Corresponding author: Hui Han, hanhui@chinawch.org.cn.

${ }^{1}$ National Center for Women and Children's Health, Chinese Center for Disease Control and Prevention, Beijing, China.

Submitted: February 14, 2020; Accepted: July 16, 2020

\section{REFERENCES}

1. Guo JH. Global positioning of China's aging and the problems and solutions of China's aging research. Acad Res 2016(2):61- 7 . http://dx.doi.org/10.3969/j.issn.1000-7326.2016.02.010. (In Chinese).

2. Center for Health Statistics and Information, NHFPC. An analysis report of national health services survey in China, 2013. Beijing: Peking Union Medical College Press, 2015. http://www.nhc.gov.cn/mohws bwstjxxzx/s8211/201610/9f109ff40e9346fca76dd82cecf419ce.shtml. (In Chinese).

3. Ma LJ. Health services research of elderly population in western rural areas. J Liuzhou Teach Coll 2015;30(2):77 - 9, 98. http://dx.doi.org/ 10.3969/j.issn.1003-7020.2015.02.021. (In Chinese).

4. Tang Y, Chen ZY, Dai AP. Health status of the unattended elders and health service utilization in western minority areas. Chin Gen Pract 2009;12(13):1194 - 5. http://dx.doi.org/10.3969/j.issn.1007-9572. 2009.13.017. (In Chinese).

5. Xu T, Han H, Pan XP. Analysis on the two-week morbidity rates and utilization of health services for elderly residents in project areas of Yunnan Province. Chin J Health Educ 2019;35(5):446-9. http://dx.doi.org/10.16168/j.cnki.issn.1002-9982.2019.05.014. (In Chinese).

6. Pan Q, Guo LX, Xiao CC, Xu YY, Chen G, Wang YY, et al. Investigation on health status of elderly people in Hubei province. Chin J Geriatr 2016;35(6):672 - 6. http://dx.doi.org/10.3760/cma.j.issn. 0254-9026.2016.06.025. (In Chinese).

7. Zhou CC, Chu J, Liu DM, Zheng WG, Guo XL, Xu LZ. Comparison of health need and utilization between empty-nest and non-empty-nest aging population in urban communities: A sample survey based on Jinan city. Chin J Health Policy 2012; 5(2): 24-9. http://journal. healthpolicy.cn/html/20120205.htm. (In Chinese).

8. Zhuang DN, Yu Y, Yang YX. Demand and utilization of community health services for elderly people in island fishing and rural areas. Chin J Gerontol 2013;33(23):5978 - 80. http://dx.doi.org/10.3969/j.issn. 1005-9202.2013.23.090. (In Chinese).

9. Ye YH. Research on the demand of health management services for the elderly in old-age care institution [dissertation]. Hangzhou: Hangzhou Normal University; 2015. http://d.wanfangdata.com.cn/thesis/D701013. (In Chinese).

10. Shi YX, Pan YH, Wang GR, Lin YM, Li Z. Survey on the prevalence rate for two-week of the old elderly in urban area in Shanghai. Chin Health Serv Manage 2005;21(2):117 - 9. http://dx.doi.org/10.3969/ j.issn.1004-4663.2005.02.025. (In Chinese). 